\title{
A Study on the Current Status of Physical Activities Among Secondary School Graduation Classes by Taking 5 Secondary Schools in Wuhan Economic Development Zone as An Example
}

\author{
Jian-Long QIAN \\ Sports Institute, Jianghan University, P.R. China \\ qjijcg@126.com
}

Keywords: High school graduating class; Sports teaching; the current situation; Countermeasure

\begin{abstract}
Through questionnaire investigation and literature studies, an investigation of the ex-curricular sports activities of the student in 5 high schools, in 25 graduating class was conducted. The results showed as follows: Physical concepts of Schools and teachers is fall behind, unreasonable teaching time and inappropriate activities, hardware and facilitates is out of date. such kind of weak consciousness restricts the development of sports teaching graduating class. So it boost the school to restore their idea of quality education in order to strengthen the middle school students' sports consciousness. Right crop for right time, so it's time to make comprehensive and reasonable teaching goals, to raise the funds investment, to enhance physical security class. To foster a good atmosphere of campus sports, to implement measures to realize the prospect of citizens, to make the middle school sports get healthy development.
\end{abstract}

\section{Preface}

With the reform of new curriculum standard in China, people pay more and more attention to the importance of physical education for adolescent physical and mental development. High school graduates as middle school students in a special group, and they face the strong social education and employment pressure, and parents' expectations in the family and they also face the pressure to realize their dreams and aspirations and other multiple pressures. Although the physical health of this special group has gained the attention from the schools and parents. In this special period, the physical health of recessive benefit and long-term benefit in some extent. They also had to give way to the entrance of the dominant and short-term benefits. Therefore, in order to promote the physical and mental health, the seniors and physical activity of high school graduates is necessary to conduct a comprehensive and in-depth research.

\section{Object and Method}

\section{Research Object}

In September 2015 to December, selected 5 middle schools and 10 high school and graduating class. There are 551 students researched, 258 of them boys, 47 per cent of those surveyed; girls 293 per cent, 53 per cent of those surveyed.

\section{Research Methods}

\section{Documentary Method}

Related to such academic websites by searching CNKI and VIP about middle school sports teaching of the literature on the topic demonstrates, for the follow-up study lays a theoretical foundation.

\section{Questionnaire}

551 questionnaires were issued, 538 copies of questionnaires, which were 519 valid questionnaires, questionnaires effective rate was 94.5 . 


\section{Interviews}

Through the visit and investigation of the Wuhan City Economic Development Zone in the third grade of the class teacher, a total of 25 sports teachers, to understand their current school sports activities for the current views and views.

\section{Results and Analysis}

\section{Students' Attitudes towards Extracurricular Sports Activities}

Most graduate students have a more explicit attitude towards extracurricular sports activities, and more than $30 \%$ of students hold "general" and "dissatisfied" attitudes. The results of the survey are shown in Table 1.

Table 1 Wuhan Economic Development Zone graduates on the attitude of sports activities $(\mathrm{N}=$ 519)

\begin{tabular}{|l|l|l|}
\hline Degree of Satisfaction & Number & $\%$ \\
\hline Satisfaction & 349 & 67.4 \\
\hline General & 107 & 20.8 \\
\hline Dissatisfaction & 63 & 11.8 \\
\hline
\end{tabular}

\section{Motivation for Extracurricular Sports Activities}

The survey shows that the motivations for graduating class students to participate in extracurricular sports activities are diversified. The main values of students' participation in extracurricular sports activities are the easing of learning pressure, physical fitness, fun and entertainment. This shows that students in secondary school graduation classes have a clearer idea of the purpose and significance of extracurricular sports activities. They understand the importance of physical activity to enhance physical fitness and slow down the learning pressure.

Table 2 Wuhan Economic Development Zone graduates to participate in sports activities of the motive (multiple choice) $(\mathrm{N}=519)$

\begin{tabular}{|l|l|l|}
\hline Motivation & Number & $\%$ \\
\hline Satisfied to enhance physical fitness & 365 & 63.1 \\
\hline Relieve learning pressure & 407 & 78.5 \\
\hline Fun & 73 & 14.2 \\
\hline Improve the level of exercise & 370 & 7.14 \\
\hline Others & 117 & 22.6 \\
\hline
\end{tabular}

\section{The Number and Time of Extracurricular Sports Activities}

It can be seen from Table 3 that the number of graduates who participated in 5 or more extracurricular sports activities per week was $15 \%$, and the frequency of extracurricular sports activities was about 2 times. About $22.2 \%$ of the graduates did not participate in any extracurricular sports activities. 
Table 3 The Number of Graduates of Wuhan Economic Development Zone Participating in Physical Activities $(\mathrm{N}=519)$

\begin{tabular}{|l|l|l|}
\hline Times & Number & $\%$ \\
\hline More than 5 times & 77 & 15 \\
\hline 2-5 times & 82 & 15.8 \\
\hline less than 2 times & 242 & 46.8 \\
\hline Nerver & 115 & 22.2 \\
\hline
\end{tabular}

As can be seen from Table 4, there are nearly half of the students who have participated in extracurricular sports activities for 30 to 60 minutes, while girls spend 30 minutes, and boys and girls have the number of participants with the extension of the time cut back. Graduation class students to participate in extracurricular sports activities and the number serious is lack of time, on the one hand may be graduating class students face great pressure to study, there is no time to participate or no time to take into account extracurricular sports activities; the other hand, the school think highly of the examination. Due to physical and psychological differences of boys and girls, the frequency and time of participation in the movement are different. The time and frequency of girls to participate in extracurricular sports activities were significantly lower than boys, reflecting the personality traits between girls and boys.

Table 4 The Number of Graduates of Wuhan Economic Development Zone Participating in Physical Activities ( $\mathrm{N}=519)$

\begin{tabular}{|l|l|l|l|l|}
\hline Time & Boys & $\%$ & Girls & $\%$ \\
\hline$<30$ & 129 & 25 & 111 & 21.4 \\
\hline $30 \sim 60{ }^{\prime}$ & 94 & 18.3 & 67 & 13 \\
\hline$>60$ & 63 & 12.2 & 51 & 10 \\
\hline
\end{tabular}

\section{Extracurricular Sports Activities Major Projects}

Male and female students have obvious gender characteristics when choosing sports events. Boys are fond of the activities of large, competitive and confrontational strong ball project. And girls often have to choose that there is a certain fitness and entertainment nature of the ball and fitness projects. The results are shown in Table 5.

Table 5 Wuhan Economic Development Zone graduates extracurricular sports activities of the project table (multiple choice) $(\mathrm{N}=519)$

\begin{tabular}{|l|c|c|c|c|}
\hline Project & Boys & Boys accounts for (\%) & $\begin{array}{r}\text { Girls' } \\
\text { number }\end{array}$ & Girls accounts for (\%) \\
\hline Basketball & 63 & 12 & - & - \\
\hline Footbal & 57 & 11 & - & - \\
\hline Swimming & 26 & 5 & 26 & 5 \\
\hline Volleyball & 112 & 21.7 & 42 & 8 \\
\hline Ping-pong & 105 & 20.3 & 126 & 24.3 \\
\hline Bandmanton & 102 & 19.6 & 186 & 35.7 \\
\hline Jogging & 126 & 24 & 83 & 16.1 \\
\hline Skipping & - & - & 155 & 30 \\
\hline
\end{tabular}




\section{The Main Factors in Influencing the Participation in Extracurricular Sports Activities}

The burden of school, the shortage of equipment, the lack of appropriate sports is the main factors of graduating class students to participate in extracurricular sports activities. There are more than half of the graduating class students have "school burden" to affect their participation in extracurricular sports activities, which is the primary factor. The survey is shown in Table 6.

Table 6 Reasons for the participation of graduates of Wuhan Economic Development Zone in participating in physical exercise (multiple choice) $(\mathrm{N}=519)$

\begin{tabular}{|l|l|l|}
\hline Reasons & Numbers & $\%$ \\
\hline Burden of study & 316 & 61 \\
\hline Sports facilities are not perfect & 67 & 13 \\
\hline No time & 134 & 26 \\
\hline Not willing & 293 & 55.4 \\
\hline Others & 93 & 18 \\
\hline
\end{tabular}

Therefore, the expansion of sports venues, to increase the emerging sports equipment has become an urgent need to solve the problem.

\section{Teachers, Parents of Students on the Attitude of Sports Activities}

The survey showed that $48 \%$ of the teachers were encouraged students to actively participate in activity but there were still $52 \%$ of the teachers who did not have any expressed attitudes and clear objections. In the case of parents (Table 8 ), 30\% of those who are encouraged to actively participate in activity, there is no expressed attitude and 34\%, respectively, still $36 \%$ of parents do not support children to participate in sports activities. It can be seen, there are many teachers and parents lack of understanding of sports activities. Improving the enthusiasm of students graduating class sports activities, students, schools, teachers, parents of the three parties should arm with the active cooperation.

\section{Conclusion and Suggestions}

However, there are still some problems, mainly in the parents and teachers' sports values are not strong, the teaching time and content are unreasonable, the sports hardware is out of date and the security consciousness is weak. The sports and sports activities of the secondary school graduating class in Wuhan Economic Development Zone need to improve. In view of the existing problems, from the vigorously promote the reform of school physical education, to establish the concept of quality education, strengthen the parents, the teacher's sports awareness, due to local conditions, to develop comprehensive and reasonable teaching objectives; Sports facilities and funding to enhance the safety awareness of physical education classroom; To cultivate a good campus sports environment, the formation of teachers and students to participate in the movement of the campus atmosphere.

\section{Acknowledgement}

1. Part of the results of 2013 the Ministry of Education Humanities and Social Sciences planning fund, project number: 13YJA890020.

2. Qian Jianlong (1965 - ), male, Professor, master of Applied Psychology tutor. Zip code 430056, E-mail: qjljcg@126.com Tel: 13545150128 


\section{References}

[1] The ministry of education, the ministry of education on national student physique and health survey in 2005 announcement, from the art [2006] no. 3. The ministry of education.2 (2006).

[2] Wei Jing, Shijiazhuang City junior middle school sports present situation and countermeasure research, Shijiazhuang: Hebei Normal University.5 (2006) 5-6.

[3] Chen Jia, Sichuan Province rural school sports status and development strategy research Sichuan University. 6(2007) 14-16.

[4] Zhou Dseng Song editor, School Physical, People's Sports Press, 2004, pp .221-225.

[5]Journal of Beijing Sport University, Journal of Beijing Sport University1 (1990), 1-5.

[6] Sun Shengling, Zhang Bo, Cui Yingcheng, Middle school physical education present situation and thinking, Liaoning Sports Science and Technology .4(2009), 84.

[7] Ren Lianxiang, School sports should be lifelong sports as the strategic focus of education, Journal of Northwest Normal University.1 (2007) 24-28. 